\title{
Tuberculosis and HIV co-infection in European Union and European Economic Area countries
}

\author{
L. Pimpin*, L.N. Drumright*,\#, M.E. Kruijshaar*, I. Abubakar*, B. Rice", V. Delpech", \\ V. Hollo ${ }^{+}$, A. Amato-Gauci ${ }^{+}$, D. Manissero ${ }^{+}$and C. Ködmön ${ }^{+}$
}

ABSTRACT: In order to ensure the availability of resources for tuberculosis (TB) and HIV management and control, it is imperative that countries monitor and plan for co-infection in order to identify, treat and prevent TB-HIV co-infection, thereby reducing TB burden and increasing the years of healthy life of people living with HIV.

A systematic review was undertaken to determine the burden of TB-HIV infection in the European Union (EU) and European Economic Area (EEA). Data on the burden of HIV infection in TB patients and risk factors for TB-HIV co-infection in the EU/EEA were extracted from studies that collected information in 1996 and later, regardless of the year of initiation of data collection, and a narrative synthesis presented.

The proportion of HIV-co-infected TB patients varied from 0 to $15 \%$. Western and eastern countries had higher levels and increasing trends of infection over time compared with central EU/EEA countries. Groups at higher risk of TB-HIV co-infection were males, young adults, foreignborn persons, the homeless, injecting drug users and prisoners.

Further research is needed into the burden and associated risk factors of co-infection in Europe, to help plan effective control measures. Increased HIV testing of TB patients and targeted and informed strategies for control and prevention could help curb the co-infection epidemic.

KEYWORDS: Co-infection, Europe, HIV, risk factors, surveillance, tuberculosis

$\mathbf{T}$ uberculosis (TB) and HIV are global public health problems with considerable interaction. TB has been identified as one of the leading causes of death among HIV-infected persons [1]. People living with HIV/AIDS (PLWHA) infected with Mycobacterium tuberculosis are at 10 times greater risk of developing TB compared with HIV-uninfected persons [2]. TB is often difficult to diagnose in a person infected with HIV due to the atypical presentation of the disease [3, 4]. The presence of TB also complicates HIV infection through a number of mechanisms including increased viral replication and CD4/CD8 cell proliferation [5]. In addition, TB-HIV co-infection complicates the management of both diseases, with drug interactions, overlapping toxicity profiles, immune reconstitution inflammatory syndrome and a high tablet burden required to treat both diseases, which may reduce adherence [6] Nevertheless, data suggest that early TB treatment in HIV-infected people reduces morbidity and mortality, and appropriate treatment regimes are often successful [7].

In order to respond to the increasing commitment to provide comprehensive care and support to HIV-infected TB patients, information is needed on the burden of co-infection and how this changes over time, particularly among at-risk populations. This information can influence policy and help secure resources for preventing, detecting and treating TB-HIV co-infection. In the European Union (EU)/European Economic Area (EEA), information on the burden of TB-HIV co-infection and risk groups appears limited. To our knowledge, there are no published systematic reviews on this topic. Annual data collection rounds of the European Centre for Disease Prevention and Control (ECDC) have estimated HIV co-infection levels for 2008 in EU/EEA countries to range between $0 \%$ of TB cases in central EU countries to $14.6 \%$ in Portugal $[8,9]$. However, 16 out of the 30 EU/EEA countries did not report numbers of TB
AFFILIATIONS

*Tuberculosis Section, Respiratory Diseases Dept,

"HIV and AIDS Reporting Section, HIV and STI Dept, Health Protection Services, Health Protection Agency, and

${ }^{*}$ Centre for Infection Prevention and Management, Infectious Diseases and Immunity, Dept of Medicine, Imperial College London, London, UK.

${ }^{+}$European Centre for Disease Prevention and Control, Stockholm, Sweden.

CORRESPONDENCE

C. Ködmön

European Centre for Disease

Prevention and Control

Tomtebodavägen $11 \mathrm{~A}$

S-171 83 Stockholm

Sweden

E-mail: Csaba.Kodmon@

ecdc.europa.eu

Received:

Dec 222010

Accepted after revision:

April 252011

First published online:

July 072011

Online ISSN 1399-3003 
cases with HIV infection to ECDC in 2008. We conducted a systematic review to improve understanding of TB-HIV coinfection levels and risk factors in EU/EEA countries.

\section{METHODS}

We performed a systematic review of published literature and other sources not commercially published or peer reviewed, such as reports, government and academic data ("grey literature"), which provided information on the burden of TB-HIV co-infection and/or risk factors for co-infection in EU/EEA counties in all European languages.

\section{Search strategy}

10 academic literature databases were searched between September and October 2009: Medline, Scopus, BIOSIS, Embase, CINAHL (Cumulative Index to Nursing and Allied Health Literature), Web of Science, DARE (Database of Abstracts of Reviews of Effectiveness), Global Health, Index to Theses and ELDIS (Electronic Development and Environment Information System). We included different terms for "TB", "HIV", "HIV/ AIDS" and "Europe" in a number of European languages (e.g. "SIDA", "tuberculose"). These were combined with the following qualifiers: "co-infection", "coinfection", "surveillance", "prevalence" or "incidence".

Google Scholar was used for a general search of the grey literature and the "related topics" search on all relevant information was used to maximise findings. Additionally, all EU/EEA countries' Ministry of Health/Statistics websites were searched for TB and HIV reports published in the last $10 \mathrm{yrs}$, and any reports/manuscripts on TB-HIV co-infection. We also asked ECDC national TB and HIV contacts to identify additional reports or documents on TB-HIV co-infection for their country in our survey of national contact points [10]. While the association of TB disease with HIV infection could more appropriately be referred to as "co-morbidity", the term "coinfection" is most widely used in the literature and was therefore used here to signify the concurrent presence of TB disease with HIV infection.

The primary concern of the initial search was sensitivity. Specificity was ensured by abstract/title and full document review. Relevant studies were obtained without language restrictions.

\section{Inclusion/exclusion criteria}

The titles and abstracts of all documents identified were screened by one main reviewer (L. Pimpin) for TB-HIV co-infection incidence, prevalence or risk factor data within EU/EEA countries. Second reviewers (L.N. Drumright and M.E. Kruijshaar) validated the inclusion process by screening $50 \%$ of the titles/abstracts, demonstrating that no potential publications were missed. The full text versions of all documents fulfilling the initial criteria, and those lacking abstracts, were retrieved. These were reviewed by one main reviewer, with $10 \%$ assessed by a second reviewer, identifying no disagreements. All documents meeting inclusion criteria for title/abstract review and reporting on 1) the number/proportion and/or rate of HIV co-infection among TB cases or 2) risk factors for TB-HIV co-infection compared with mono-infected HIV or TB cases, or nondiseased persons, were included.
Only the most complete and recent information was extracted in instances where there were multiple published estimates of the same data, to avoid duplication. National publications were given precedence over international publications, as these were considered to be closer to the source, regardless of differences in data reported. Studies from any non-EU/EEA countries were excluded, as were literature reviews, summaries and case reviews. Studies providing data collected only before 1996 were excluded, as the aim of this review was to examine current trends in co-infection in the era after introduction of highly active antiretroviral therapy (HAART). However, publications covering periods both before and after 1996 were included in order to capture as much information as possible.

\section{Data extraction}

Data were extracted using a pre-defined Excel database by one reviewer, with $10 \%$ validation by a second reviewer. Information collected included study and participant characteristics, numbers and proportions of co-infection and/or risk factors, as well as potential biases and points raised in the discussion, such as testing/screening methods and coverage, assessment of coinfection status and other relevant background information.

\section{Data analysis}

Estimates of co-infection were expected to differ between countries and data sources (i.e. national surveillance and local or hospital populations). Therefore, no attempt was made to pool data, a descriptive synthesis was undertaken, and recent trends described.

\section{RESULTS}

Following removal of duplicates and initial abstract review, we identified 380 papers for full text retrieval from 6,632 references in the published and grey literature. After full inspection, 61 documents were included (54 on burden of TB-HIV only, six providing risk factor information only, and one presenting both). The full details of the article retrieval process are summarised in figure 1 . Nine studies provided data on the number of PLWHA co-infected with TB, which are not included in this study.

\section{Study characteristics}

All 55 documents providing information on the burden of TBHIV co-infection reported prevalence of HIV in TB patients, with one also measuring incidence [11]. The majority of papers provided national estimates (37 $(67 \%)$ out of 55$)$, the remaining regional or local. The greatest number of studies was from Spain, followed by France. For 19 countries the only sources of data were from four international surveillance reports $[8,12-14]$. Information on sociodemographic characteristics of patients was provided in 26 studies.

The seven risk factor studies were from Spain (five out of seven), France and the Netherlands. Most were longitudinal studies (four out of seven), one was cross-sectional and two were obtained from surveillance studies. The majority of papers (five out of seven) presented risk factors for co-infection, with PLWHA as the baseline population.

\section{Overall burden of TB-HIV co-infection}

Data on HIV co-infection among TB patients was identified for 23 out of the 30 EU/EEA countries. The most recent national 


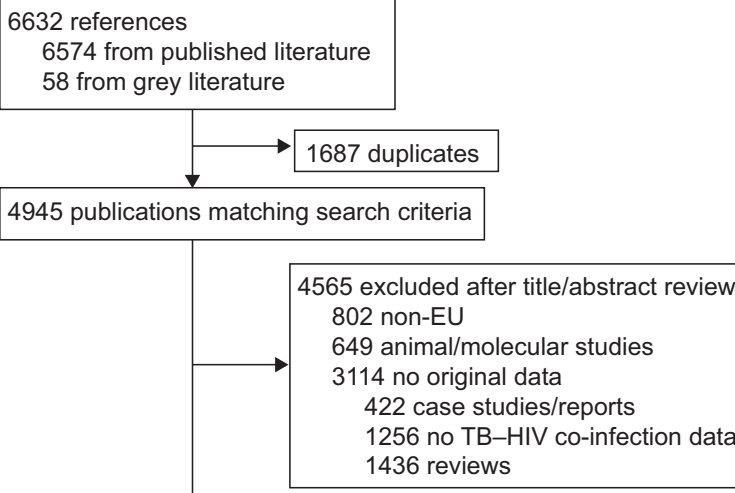

380 for full text retrieval after title/abstract review

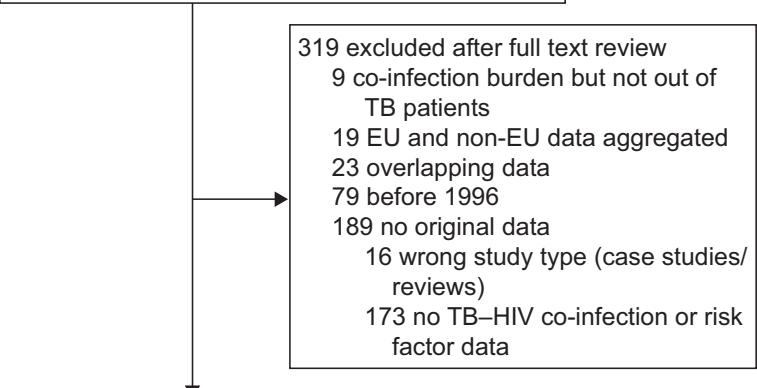

61 included and extracted after full text review

55 burden data

7 risk factor data

FIGURE 1. Flow chart of inclusion of manuscripts for the primary and secondary outcomes. EU: European Union; TB: tuberculosis.

estimates are shown in table 1 and figure 2. Prevalence varied between $0 \%$ in Bulgaria, Slovenia and Slovakia to $15 \%$ in Portugal and Iceland. In general, a very low level of co-infection was observed in central EU/EEA countries. Information on the burden of co-infection in capital cities was available for four countries. The prevalence was 7.3\% in London (in 2005), $7.5 \%$ in Paris (in 2001), 8.6\% in Brussels (in 2008) and 14.3\% in Madrid (in 2003). Except for London, where prevalence was the same as the national average, the co-infected proportion in these cities was higher than the national average.

\section{Trends in TB-HIV co-infection}

Between 2000 and 2008, Estonia, Latvia, Lithuania, Belgium, Denmark and England and Wales, as well as the Czech Republic and Romania, reported increasing proportions of HIV co-infection among TB patients, although in some this reached a plateau in the latest years of observation (fig. 3). Data for France are also suggestive of an increase in co-infection, but additional time-points are required to confirm this. Spain and Portugal show a decline in co-infection levels, and Finland may be exhibiting a downward trend.

\section{Characteristics of co-infected cases}

Demographic characteristics were reported for few countries, and the most recent data are shown in figure 4 . The majority of co-infected cases were male and young adults (fig. $4 a$ and b), and their proportion was larger than in non-co-infected patients.

\begin{tabular}{|c|c|c|}
\hline $\begin{array}{l}\text { Proportic } \\
\text { infected } \\
\text { Econom }\end{array}$ & \multicolumn{2}{|c|}{$\begin{array}{l}\text { Proportions of tuberculosis (TB) patients co- } \\
\text { infected with HIV in European Union/European } \\
\text { Economic Area countries }\end{array}$} \\
\hline Country [ref.] & Year & $\begin{array}{l}\text { TB patients with } \\
\text { HIV n/N (\%) }\end{array}$ \\
\hline Austria [13] & 2005 & 16/942 (1.7) \\
\hline Belgium [15] & 2008 & $56 / 1006(5.6)$ \\
\hline Bulgaria [8] & 2008 & 0/3151 (0) \\
\hline Cyprus [8] & 2008 & $2 / 50(4)$ \\
\hline Czech Republic [8] & 2008 & $7 / 868(0.8)$ \\
\hline Denmark [16] & 2008 & $4 / 367(1.0)$ \\
\hline Estonia [8] & 2008 & $44 / 444(9.9)$ \\
\hline Finland [8] & 2006 & 6/297 (2) \\
\hline France [8] & 2001 & $364 / 6465$ (5.6) \\
\hline Iceland [8] & 2006 & 2/13 (15.4) \\
\hline Ireland [8] & 2008 & 15/470 (3.2) \\
\hline Italy [13] & 2005 & $121 / 3975(3.0)$ \\
\hline Latvia [8] & 2008 & $72 / 1070$ (6.7) \\
\hline Lithuania [8] & 2007 & 21/2408 (0.9) \\
\hline Malta [8] & 2008 & $5 / 53(9.4)$ \\
\hline The Netherlands [17] & 2008 & $37 / 997$ (3.7) \\
\hline Poland [18] & 2004 & $15 / 9493(0.2)$ \\
\hline Portugal [8] & 2008 & 438/2995 (14.6) \\
\hline Romania [8] & 2008 & 202/24786 (0.8) \\
\hline Slovakia [8] & 2008 & 0/633 (0) \\
\hline Slovenia [8] & 2008 & $0 / 213(0)$ \\
\hline Spain [8] & 2008 & $507 / 8214(6.2)$ \\
\hline England and Wales [19] & 2005 & 233/3153 (7.4) \\
\hline
\end{tabular}

All data were based on national surveillance. The burden in some countries with low numbers of TB cases, e.g. Iceland, must be interpreted with caution.

In northwestern EU countries, cases were mostly foreign born while in Spain and Italy around 30\% were foreign born.

In Spain, a large proportion of co-infected cases were intravenous drug users (IDU) compared with all TB cases (59\% versus $8 \%$, respectively). Although no comparable mono-infected data were available, Latvia showed a similarly high proportion of IDU co-infected cases.

\section{Risk factors for TB-HIV co-infection}

In the seven papers that statistically examined risk factors for TB/HIV co-infection, sex, age, CD4 count at HIV diagnosis, HIV transmission route and TB risk groups were most often studied (tables 2-4). Co-infection was associated with male sex in three out of five studies (table 2). Younger adults (aged 25-30 to $45 \mathrm{yrs}$ ) tended to have a higher risk of TB co-infection compared with children and older adults, but this was statistically significant in only two out of the four relevant studies (table 2).

The risk of TB disease was higher in PLWHA who presented with lower CD4 cell counts $\left(<200\right.$ cells $\left.\cdot \mathrm{mm}^{-3}\right)$ at HIV diagnosis in three studies (table 3). A fourth study among AIDS patients found that TB was more likely to be reported as the AIDSdefining illness at higher CD4 counts $\left(200-350\right.$ cells $\left.\cdot \mathrm{mm}^{-3}\right)$ than other AIDS-defining illnesses. 


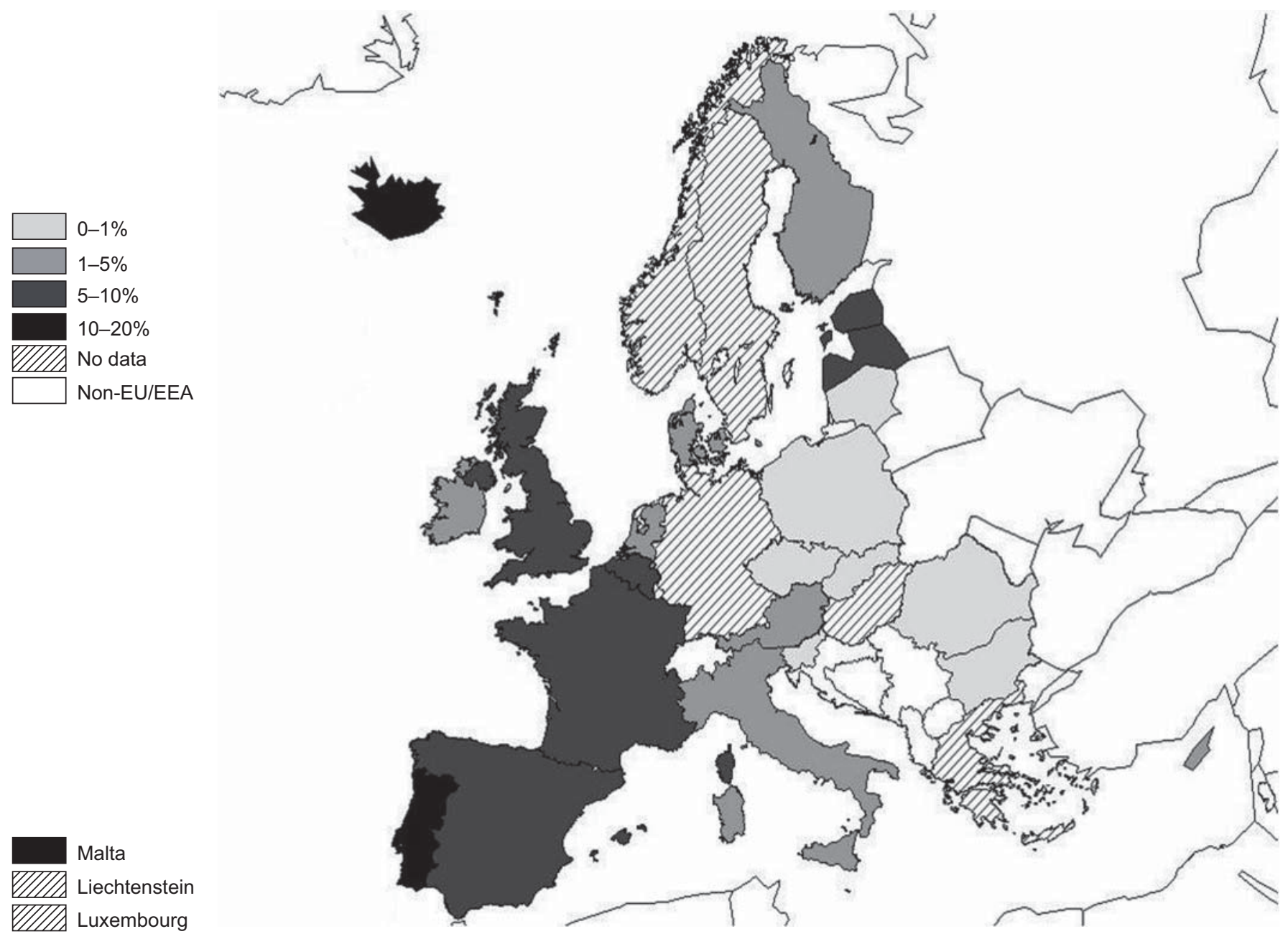

FIGURE 2. Map of the most recent data on proportions of tuberculosis (TB) patients co-infected with HIV in European Union (EU)/European Economic Area (EEA) countries All data were based on national surveillance (2001-2008). The burden in some countries with low numbers of TB cases, e.g. Iceland, must be interpreted with caution.

Acquiring HIV through injecting drugs was significantly associated with higher risk of TB co-infection than acquisition through sexual contact in three out of the four studies investigating probable route of HIV infection [29, 33, 35].

Combinations of risk behaviours and lifestyles, including homelessness, imprisonment, alcohol abuse, sharing syringes and close contact with a TB case, were associated with an increased risk of being TB-HIV co-infected (table 4).

Two studies investigated the risk of co-infection by place of birth or citizenship, showing contradictory evidence of whether being foreign born conferred increased risk of co-infection. One study from France [29] found an increased risk of TB in foreign-born PLWHA. Conversely, a Dutch study demonstrated that TB patients of Asian and eastern EU/EEA citizenship had a decreased risk of HIV diagnosis among TB patients compared with Dutch nationals [21]. When comparing such data it should be considered that the definition of citizenship might vary between countries and the ethnic distribution may vary as well. Both studies also looked at area of residence, showing a higher risk of co-infection in urban areas $(p<0.001)$ [21, 29].

\section{DISCUSSION}

Published data on the proportion of TB patients co-infected with HIV show that levels are highest in Iceland and Portugal $(15 \%)$ and lowest in central EU/EEA countries $(<1 \%)$. Increasing trends were observed in the Baltic states as well as western EU countries, the Czech Republic and Romania. Sociodemographic characteristics and risk factors for TB-HIV co-infection were only reported for a handful of countries. In these countries, males, young adults, IDU, the homeless, prisoners, those living in urban areas and, in some countries, foreign-born persons were at higher risk of co-infection.

\section{Strengths and limitations}

This review used a sensitive approach, identifying a large number of publications to ensure all information was captured. Although we were not able to check for evidence of publication bias, the comprehensive search undertaken minimised the potential for missing studies. A limitation is the inherent observational nature of surveillance studies associated with biases and confounding. Comments in our survey of national HIV and $\mathrm{TB}$ contacts to the ECDC suggest that surveillance systems may 

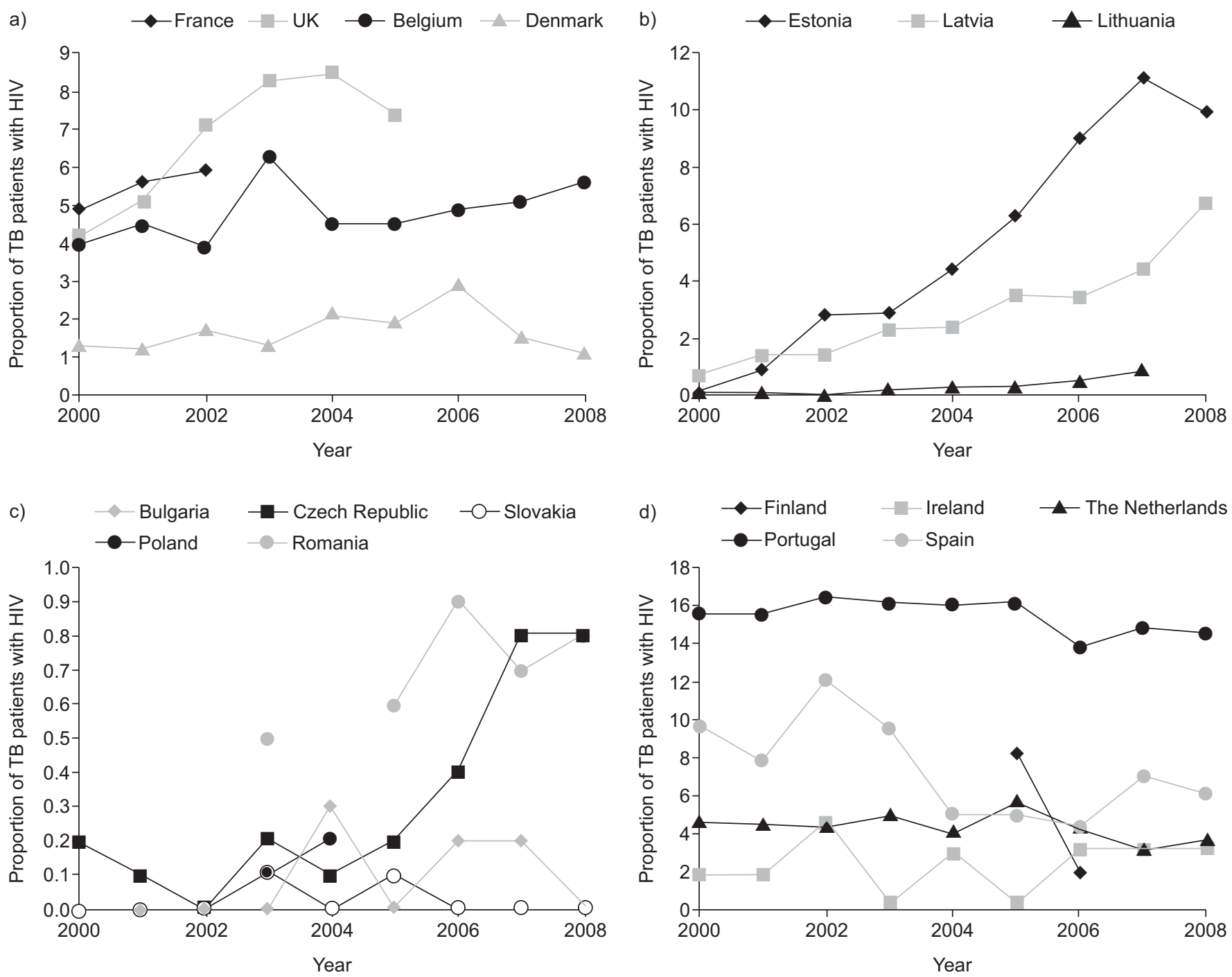

FIGURE 3. Trends in the prevalence of HIV co-infection in tuberculosis (TB) patients in European Union/European Economic Area countries by year of reporting.

under-represent marginalised populations $[9,10]$. The majority of studies presenting data on risk factors and demographic characteristics were conducted in Spain, and data were only available for a small number of countries. The heterogeneous nature of the populations and infrastructures within the EU/ EEA hinders the generalisation of this information to the whole of Europe. Furthermore, differences in the design of and populations covered by these studies only allowed for a descriptive synthesis of the evidence available. We included both demographic data from surveillance reports and risk factor data from observational studies, which increases the heterogeneity of this data. However, because of the limited number of observational studies, the demographic information was obtained to strengthen our results. Despite these limitations, findings were in agreement with knowledge on risk groups for TB and/or HIV separately, and/or studies from outside the EU/EEA, and countries with similar populations and infrastructure may be found to have similar risk groups.

This is the first comprehensive overview of this subject in the EU/EEA and it provides useful data for planning and evaluation of control measures.

\section{Trends in TB-HIV co-infection}

The distribution of co-infection across the EU/EEA is in agreement with what is reported by ECDC and in our survey of national contacts $[8,10]$. The burden of co-infection follows the national prevalence of HIV in these countries [8] and the countryspecific prevalence of drug users. Some of the observed timetrends may be due to changes in testing activity and reporting practices, and may not represent an increase in the true number of HIV-infected TB patients, but rather in the diagnosed burden. However, it is interesting to note that countries such as Spain and Italy, with higher levels of co-infection in IDU and homeless populations, show decreasing rates of TB-HIV co-infection, while countries with higher levels of HIV infection in foreignborn people had increasing rates. This suggests that the increases in some countries may be related to migration and decreases to strengthened control in IDU and homeless populations. Further efforts are required to control TB in other parts of the world to reduce the risk in migrant populations in these countries.

HIV prevalence in TB patients was generally higher in capital cities, and urban areas were found to be associated with an increased risk of co-infection. This is in agreement with 
a)

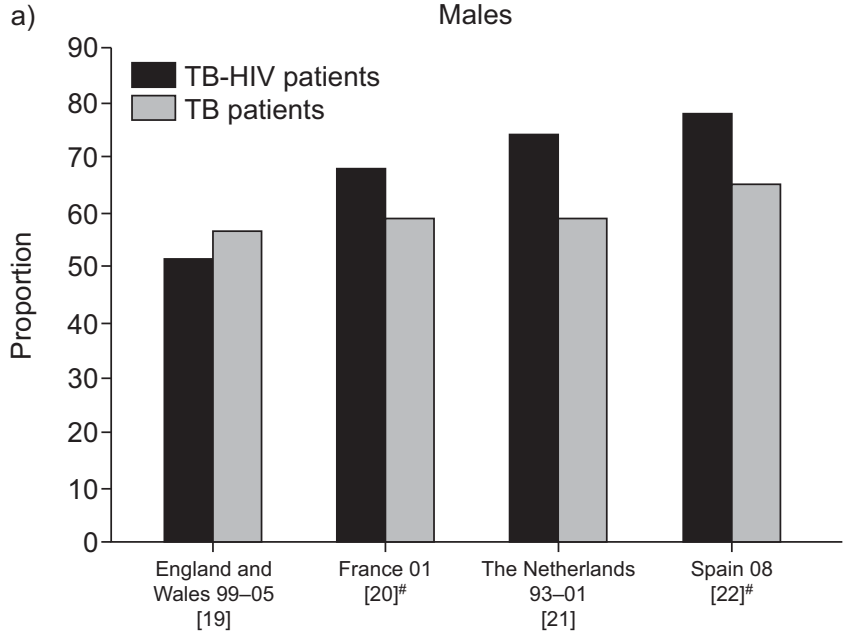

c)

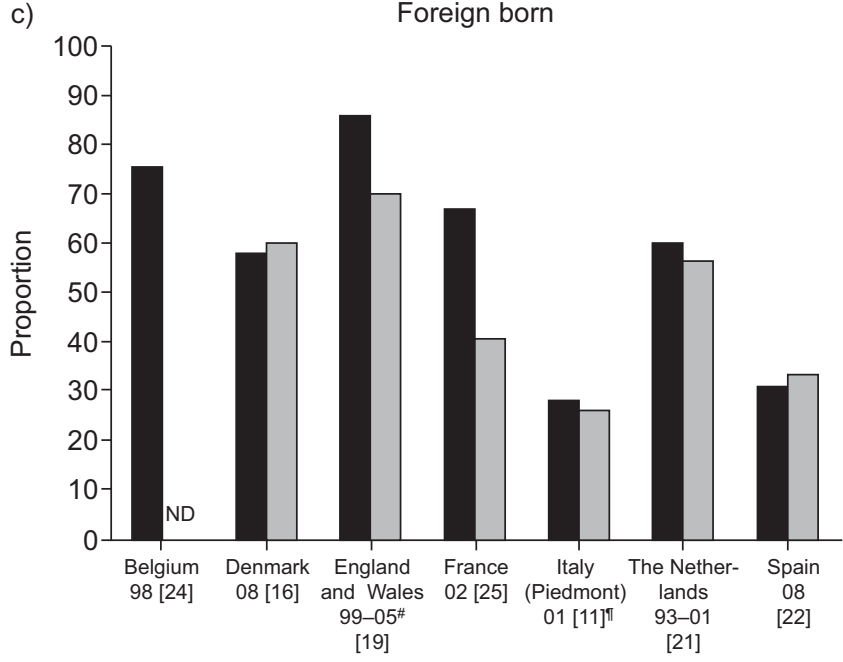

b)

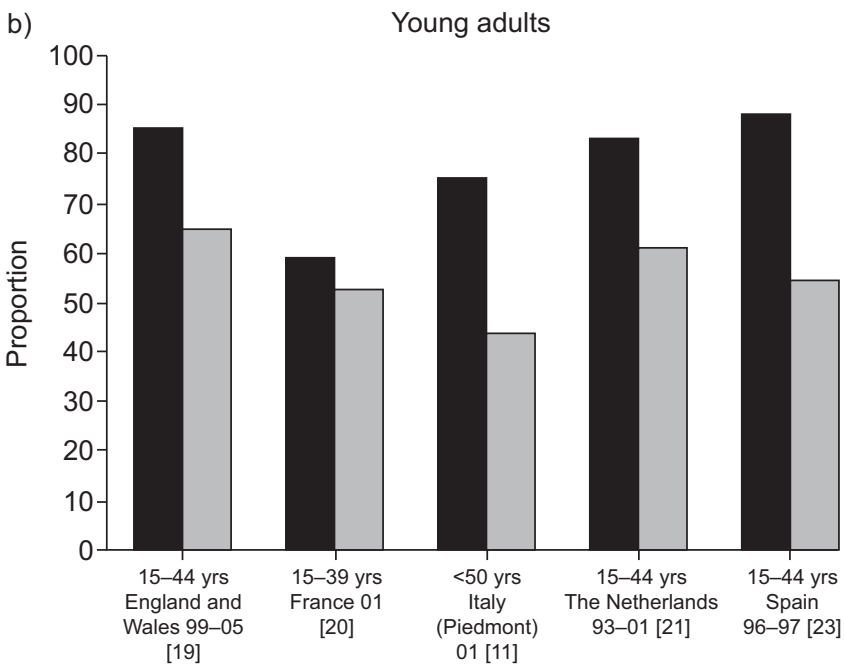

d)

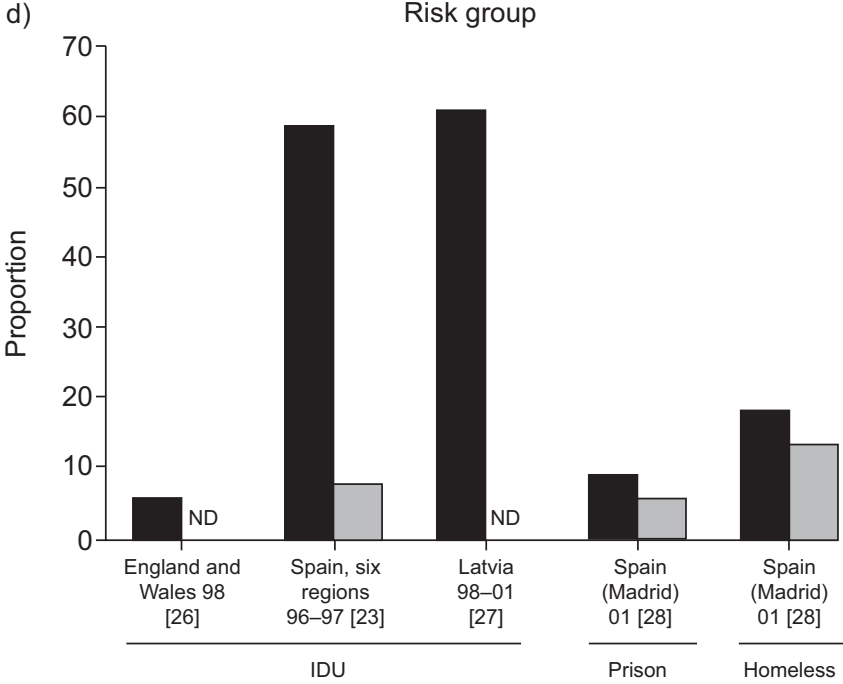

FIGURE 4. Sociodemographic characteristics of cases co-infected with HIV ( $\mathbf{\square})$ compared with mono-infected tuberculosis (TB) cases ( $\square$ ) (most recent data). Year(s) from which data were acquired and reference numbers are given for each country. All data are from surveillance apart from reference [28], which is from a cross-sectional study in more than one hospital in Madrid (Spain). ND: no data; IDU: intravenous drug users. *: unknown category not included; ": only those originating from high TB prevalence countries were included as foreign born.

previous data from non-EU countries [36] and may be related to the greater number of high-risk individuals for TB and/or HIV co-infection in these areas $[37,38]$. Urban conditions such as poverty and overcrowding have also long been associated with TB [39, 40]. Studies of hospital in-patients also tended to show a higher prevalence of HIV co-infection than the national average. This is to be expected as TB-HIV co-infected patients are more likely to have complex needs, drug interactions and toxicities, and are therefore more likely to be in contact with hospitals.

\section{Risk factors/groups for TB-HIV co-infection}

The higher risk of co-infection in males found in four studies is consistent with the observation that both TB [8] and HIV [41] are more common among males in Europe [13]. This reflects the more prominent transmission of HIV through males having sex with males and via injection of drugs, since a higher proportion of drug users is male [31, 32]. Co-infection was more prevalent in the 15-45-yr age group in five studies, reflecting the higher proportion of HIV in this group, or more frequent HIV testing in young adult TB cases [21, 29, 30]. Five out of seven countries where the data were available showed a majority of the TB-HIV co-infected patients to be born abroad. These countries have high levels of migration from parts of the world with generalised TB and HIV epidemics. Countries where the majority of migrants originate from areas with concentrated epidemics, for example Spain, which receives more migrants from LatinAmerican countries, show a different pattern of co-infection. Based on three Spanish studies, PLWHA with lower CD4 counts, mainly as a result of late diagnosis, were more likely to have TB disease compared with those with a higher CD4 count [32]. Among persons diagnosed with an AIDS-defining illness in France, TB was diagnosed at higher CD4 cell counts than other AIDS-defining illnesses. This is consistent with findings that TB 


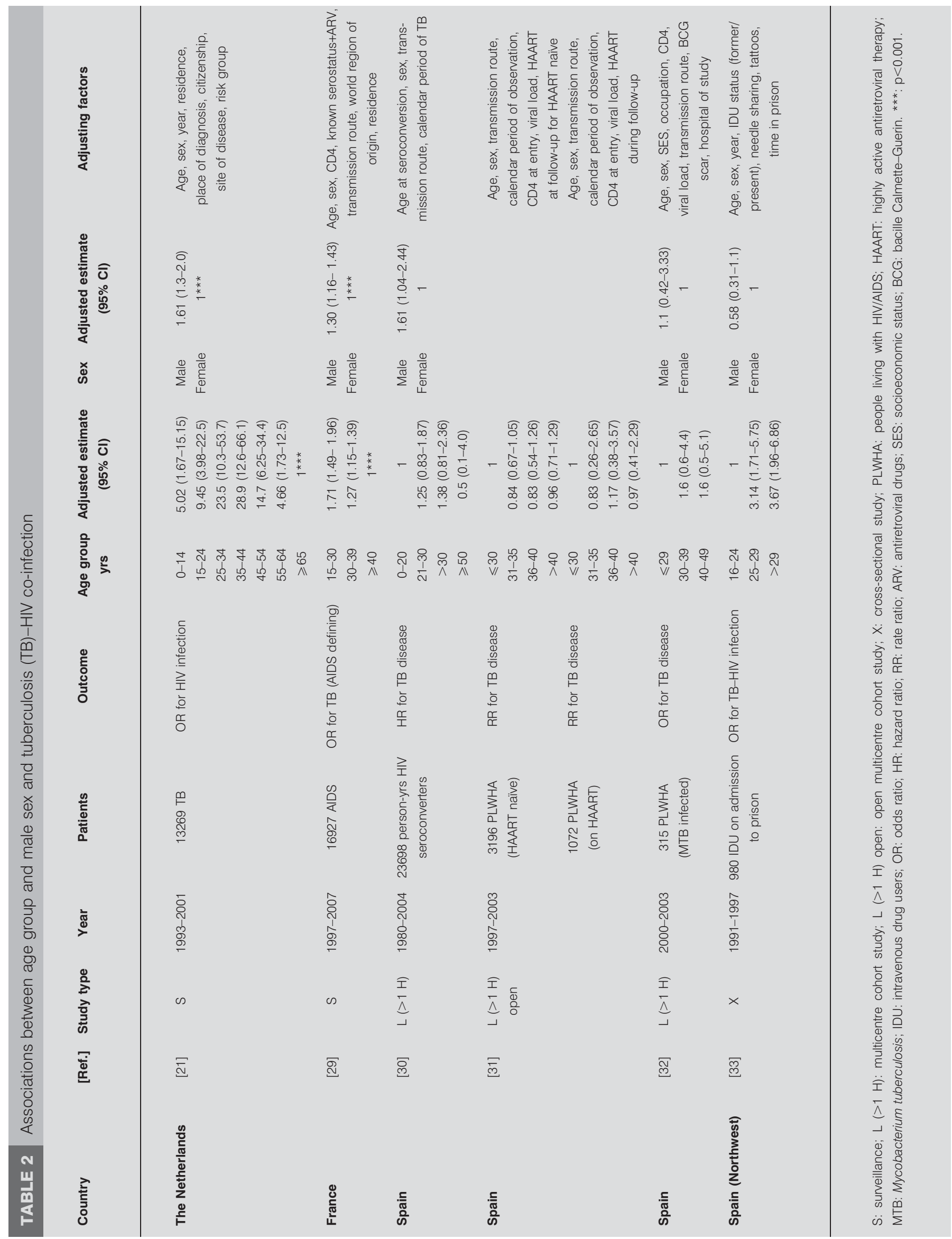




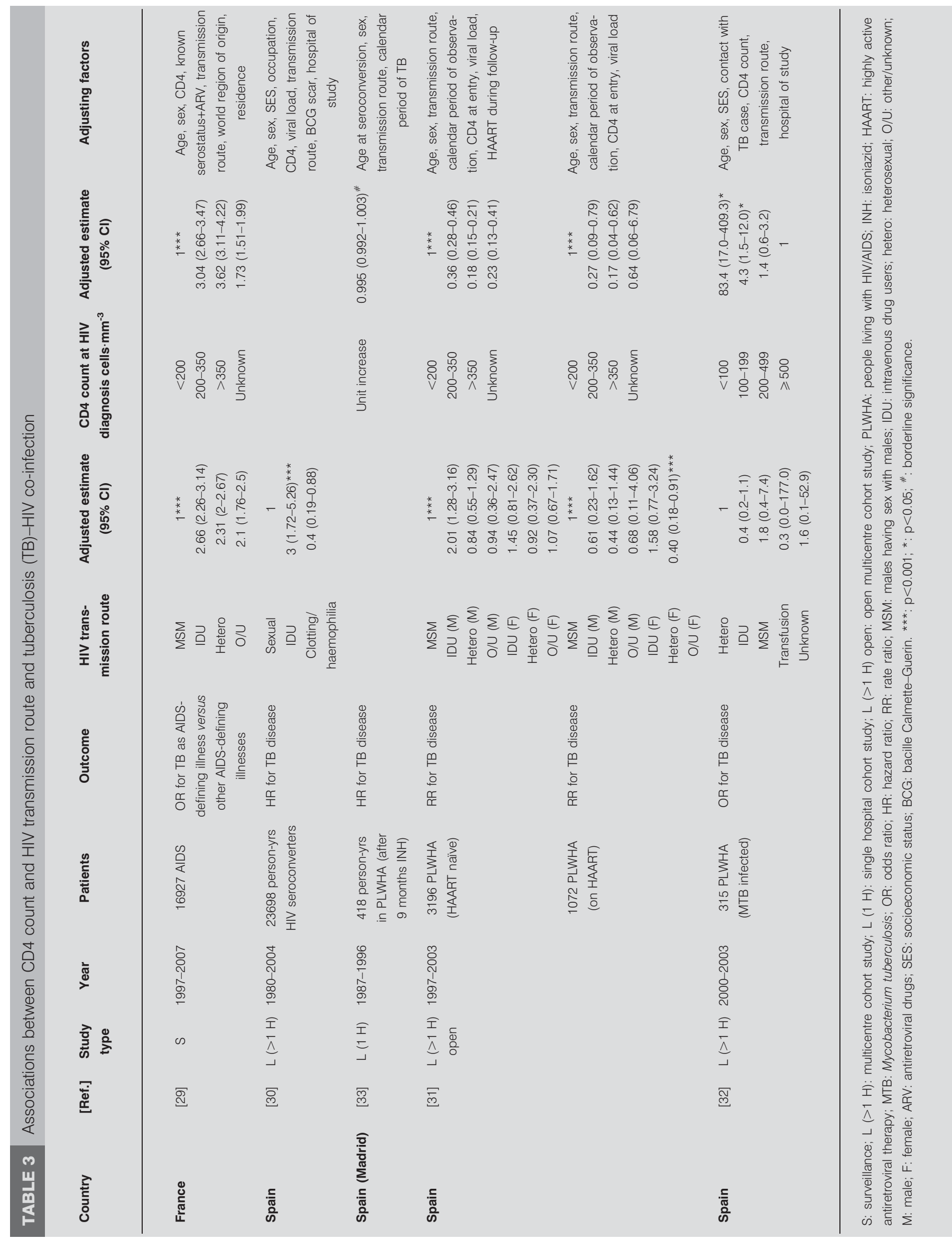




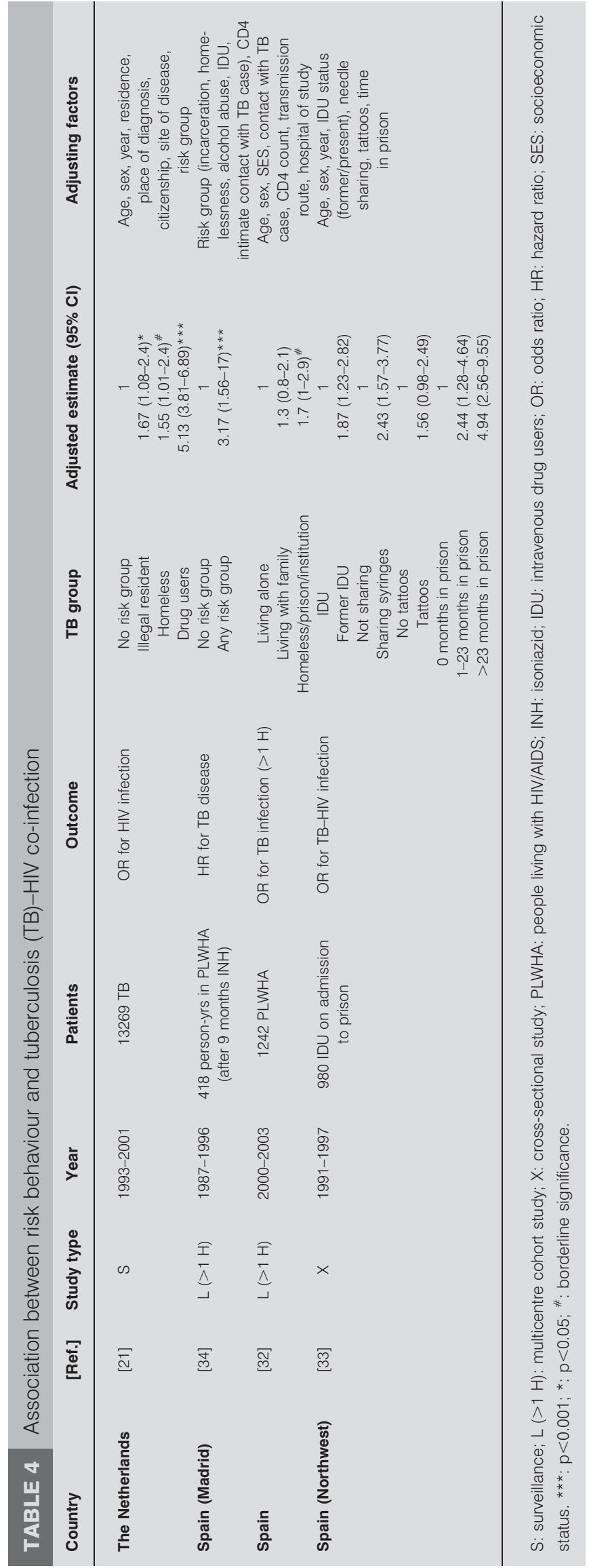

occurs earlier in HIV infection than other opportunistic diseases $[42,43]$, highlighting the need to monitor PLWHA for TB throughout the course of their infection.

Several countries have highlighted the diversity in the level of co-infection across population groups. These findings provide evidence for more robust monitoring of co-infection in EU/ EEA countries in order to develop targeted strategies to reduce HIV and TB infection. Although demographic and clinical data pertaining to persons living with HIV and/or TB are available in many countries, they are not always reported. Reporting of this information and analyses to determine statistical associations between co-infection and demographics would provide much needed information to tailor effective control strategies.

\section{Clinical implications}

The results of this review highlight how some population groups affected by TB and HIV co-infection are particularly vulnerable, suggesting that efforts for identifying, treating and raising awareness for both diseases should be considered by countries with high levels of co-infection in these populations. The survey of TB and HIV contact points shows limited overlap in risk groups targeted for TB and HIV screening; IDU and prisoners are screened for both infections in eight countries, and migrants in nine [10]. In order to capture and effectively treat all co-infected patients, some countries with higher co-infection burdens might benefit from screening risk groups for both infections. In addition, various studies have shown that many TB patients are not tested for HIV [10, 44-46]. Further improvements are needed in offering HIV testing to all TB patients, as recommended by the World Health Organization [47].

\section{Conclusion}

Co-infection levels in EU/EEA countries ranged from $0 \%$ to $15 \%$ and were in the same range as those reported from comparable parts of the world (e.g. the USA had 12\% HIV-positive TB cases in 2007, Canada had 5.7\%, Australia had 3.2\% and Japan had $0.5 \%$ [48-51]). The increasing levels observed in a number of EU/EEA countries are concerning. Efforts to scale up control of both infections as well as further monitoring of the trends of coinfection are therefore required.

Males, young adults, foreign-born people and those living in urban areas, as well as injecting drug users, the homeless and prisoners, were identified as high-risk groups for TB-HIV coinfection. The information obtained in this review indicates that a diverse and varied approach is required to deal with the burden and population groups at risk of TB-HIV co-infection in EU/EEA countries. Greater use of available demographic and clinical data, as well as further, standardised, Europe-wide research would help increase our understanding of co-infection risk.

\section{SUPPORT STATEMENT}

This work was funded by a European Centre for Disease Prevention and Control (ECDC) framework (grant contract number ECD 1632).

\section{STATEMENT OF INTEREST}

None declared.

\section{REFERENCES}

1 Sharma SK, Mohan A, Kadhiravan T. HIV-TB co-infection: epidemiology, diagnosis and management. Indian J Med Res 2005; 121: 550-567. 
2 Liberato IR, de Albuquerque MF, Campelo AR, et al. Characteristics of pulmonary tuberculosis in HIV seropositive and seronegative patients in a Northeastern region of Brazil. Rev Soc Bras Med Trop 2004; 37: 46-50.

3 Mendelson M. Diagnosing tuberculosis in HIV-infected patients: challenges and future prospects. Br Med Bull 2007; 81-82: 149-165.

4 Sterling TR, Pham PA, Chaisson RE. HIV infection-related tuberculosis: clinical manifestations and treatment. Clin Infect Dis 2010; 50: Suppl. 3, S223-S230.

5 Toossi Z. Virological and immunological impact of tuberculosis on human immunodeficiency virus type 1 disease. J Infect Dis 2003; 188: $1146-1155$

6 Pozniak AL, Collins S, Coye KM, et al. British HIV Association (BHIVA) guidelines for the treatment of TB/HIV co-infection 2009. London, BHIVA, 2010. Available from http://www.bhiva.org/ PublishedandApproved.aspx

7 Schiffer JT, Sterling TR. Timing of antiretroviral therapy initiation in tuberculosis patients with AIDS: a decision analysis. J Acquir Immune Defic Syndr 2007; 44: 229-234.

8 Tuberculosis surveillance in Europe 2008. Stockholm, European Centre for Disease Prevention and Control, World Health Organization Regional Office for Europe, 2010.

9 Kruijshaar ME, Pimpin L, Abubakar I, et al. The burden of TB-HIV in the European Union - how much do we know? A survey of TB-HIV surveillance practices and results. Eur Respir J 2011; 38: 1374-1381.

10 Survey on TB-HIV co-infection in EU/EEA countries 2009/2010. Stockholm, European Centre for Disease Prevention and Control, World Health Organization Europe, 2011.

11 Baussano I, Bugiani M, Gregori D, et al. Impact of immigration and HIV infection on tuberculosis incidence in an area of low tuberculosis prevalence. Epidemiol Infect 2006; 134: 1353-1359.

12 EuroHIV. HIV/AIDS Surveillance in Europe. Mid-year report 2006. Report No. 74. Saint-Maurice, French Institute for Public Health Surveillance, 2007.

13 Lazarus JV, Olsen M, Ditiu L, et al. Tuberculosis-HIV co-infection: policy and epidemiology in 25 countries in the WHO European region. HIV Med 2008; 9: 406-414.

14 World Health Organization. Global Tuberculosis Control Epidemiology, Strategy, Financing. Geneva, World Health Organization, 2009.

15 Registre Belge de la Tuberculose 2008. [Belgian registry of tuberculosis 2008.] Brussels, Fonds des Affections Respiratoires, 2010.

16 Tuberculosis 2008, Part I. Copenhagen, Statens Serum Institute, 2009.

17 Tuberculosis in the Netherlands 2008. Surveillance report of the tuberculosis situation in the Netherlands. The Hague, KNCV Tuberculosis Foundation, 2009.

18 World Health Organization. Global tuberculosis control: a short update to the 2009 report. Geneva, World Health Organization, 2009. Data available from http://www.who.int/tb/publications/ global_report/2009/update/a-7_eur.pdf Date last accessed: April 5, 2010.

19 French CE, Glynn JR, Kruijshaar ME, et al. The association between HIV and antituberculosis drug resistance. Eur Respir J 2008; 32: 718-725.

20 Cailhol J, Che D, Campese C, et al. Les cas de tuberculose déclarés en France en 2001 [Cases of tuberculosis declared in France in 2001]. Arch Pédiatr 2003; 10: 476-481.

21 Haar CH, Cobelens FG, Kalisvaart NA, et al. HIV prevalence among tuberculosis patients in the Netherlands, 1993-2001: trends and risk factors. Int J Tuberc Lung Dis 2006; 10: 768-774.

22 Instituto de Salud Carlos III. Casos de tuberculosis declarados a la red nacional de vigilancia epidemiologica. Espana 2008. [Cases of tuberculosis reported to the national epidemiological surveillance. Spain 2008.]. Boletin Epidemiologico Semanal 2009; 17: 121-124.

23 Ruiz-Navarro MD, Espinosa JA, Hernandez MJ, et al. Efectos del VIH y otras variables sobre el resultado del tratamiento antituberculoso en España [Effects of HIV status and other variables on the outcome of tuberculosis treatment in Spain]. Arch Bronconeumol 2005; 41: 363-370.

24 Wanlin $\mathrm{M}$, Uydebrouck $\mathrm{M}$, Vermeire $\mathrm{P}$, et al. Recent trends in tuberculosis incidence in Belgium. Arch Public Health 2000; 58: 241-251.

25 Che D, Campese C, Decludt B. Cases of tuberculosis declared in France in 2002. Bull Epidémiol Hebdomadaire 2004; 16.

26 Rose AM, Sinka K, Watson JM, et al. An estimate of the contribution of HIV infection to the recent rise in tuberculosis in England and Wales. Thorax 2002; 57: 442-445.

27 Morozova I, Riekstina V, Sture G, et al. Impact of the growing HIV-1 epidemic on multidrug-resistant tuberculosis control in Latvia. Int J Tuberc Lung Dis 2003; 7: 903-906.

28 Garcia Sanchez I, Perez de Oteyza C, Gilsanz Fernandez C. Estudio epidemiológico de la tuberculosis en un hospital de tercer nivel en el año 2001 [Tuberculosis epidemiological study in a third level hospital during 2001]. An Med Interna 2005; 22: 222-226.

29 Lot F, Pinget R, Cazein F, et al. Frequency and risk factors for tuberculosis as an AIDS-defining illness, in France. Bull Epidémiol Hebdomadaire 2009; 113.

30 Muga R, Ferreros I, Langohr K, et al. Changes in the incidence of tuberculosis in a cohort of HIV-seroconverters before and after the introduction of HAART. AIDS 2007; 21: 2521-2527.

31 Moreno S, Jarrin I, Iribarren JA, et al. Incidence and risk factors for tuberculosis in HIV-positive subjects by HAART status. Int $J$ Tuberc Lung Dis 2008; 12: 1393-1400.

32 Diez M, Diaz A, Bleda MJ, et al. Prevalence of M. tuberculosis infection and tuberculosis disease among HIV-infected people in Spain. Int J Tuberc Lung Dis 2007; 11: 1196-1202.

33 Martin V, Cayla JA, Bolea A, et al. Mycobacterium tuberculosis and human immunodeficiency virus co-infection in intravenous drug users on admission to prison. Int J Tuberc Lung Dis 2000; 4: 41-46.

34 Casado JL, Moreno S, Fortun J, et al. Risk factors for development of tuberculosis after isoniazid chemoprophylaxis in human immunodeficiency virus-infected patients. Clin Infect Dis 2002; 34: 386-389.

35 Caminal Montero L, Trapiella Martinez L, Telenti Asensio M, et al. Características de la tuberculosis en un hospital general durante los años 1993-1998. Análisis de las resistencias y coinfection por el VIH [Characteristics of tuberculosis in a general hospital during the period 1993-1998. Analysis of resistence and HIV coinfection]. Enferm Infecc Microbiol Clin 2002; 20: 68-73.

36 Datiko DG, Yassin MA, Chekol LT, et al. The rate of TB-HIV coinfection depends on the prevalence of HIV infection in a community. BMC Public Health 2008; 8: 266.

37 Story A, Murad S, Roberts W, et al. Tuberculosis in London: the importance of homelessness, problem drug use and prison. Thorax 2007; 62: 667-671.

38 Galea S, Rudenstine S, Vlahov D. Drug use, misuse, and the urban environment. Drug Alcohol Rev 2005; 24: 127-136.

39 Elender F, Bentham G, Langford I. Tuberculosis mortality in England and Wales during 1982-1992: its association with poverty, ethnicity and AIDS. Soc Sci Med 1998; 46: 673-681.

40 Mangtani P, Jolley DJ, Watson JM, et al. Socioeconomic deprivation and notification rates for tuberculosis in London during 19821991. BMJ 1995; 310: 963-966.

41 HIV/AIDS surveillance in Europe 2008. Stockholm, European Centre for Disease Prevention and Control, World Health Organization Regional Office for Europe, 2009.

42 Sonnenberg P, Glynn JR, Fielding K, et al. How soon after infection with HIV does the risk of tuberculosis start to increase? A retrospective cohort study in South African gold miners. J Infect Dis 2005; 191: 150-158.

43 Patel NR, Swan K, Li X, et al. tuberculosis-mediated apoptosis in alveolar macrophages from HIV+ persons: potential role of IL-10 and BCL-3. J Leukoc Biol 2009; 86: 53-60. 
44 Haar CH, Cobelens FG, Kalisvaart NA, et al. [HIV-test policy for tuberculosis patients in the Netherlands]. Ned Tijdschr Geneeskd 2007; 151: 2674-2679.

45 van der Werf MJ, Yegorova OB, Chechulin Y, et al. HIV testing practices of TB patients after introduction of a new testing policy in Kiev City, Ukraine. Int J Tuberc Lung Dis 2005; 9: 733-739.

46 Rodger AJ, Story A, Fox Z, et al. HIV prevalence and testing practices among tuberculosis cases in London: a missed opportunity for HIV diagnosis? Thorax 2010; 65: 63-69.

47 Guidelines for HIV Surveillance Among Tuberculosis Patients. 2nd Edn. Geneva, World Health Organization, 2004.

48 World Health Organization. United States of America Tuberculosis Profile. Geneva, World Health Organization, 2009. Available from https: / / extranet.who.int $/$ sree $/$ Reports?op $=$ Replet\&name $=\%$ 2FWHO_HQ_Reports\%2FG2\%2FPROD\%2FEXT\%2FTBCountryProfile \&ISO2=US\&outtype $=\mathrm{html}$ Date last accessed: November 18, 2010.
49 World Health Organization. Canada Tuberculosis Profile. Geneva, World Health Organization, 2009. Available from https: / / extranet.

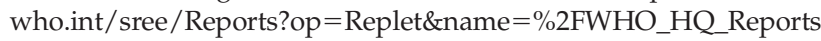
$\% 2 F G 2 \% 2 F P R O D \% 2 F E X T \% 2 F T B C o u n t r y P r o f i l e \& I S O 2=C A \& o u t t y p e$ $=\mathrm{html}$ Date last accessed: November 18, 2010.

50 World Health Organization. Australia Tuberculosis Profile. Geneva, World Health Organization, 2009. Available from https:/ / extranet.who.int $/$ sree $/$ Reports?op $=$ Replet\&name $=\% 2 \mathrm{FWHO}$ HQ_Reports\%2FG2\%2FPROD\%2FEXT\%2FTBCountryProfile\& $\mathrm{ISO} 2=\mathrm{AU} \&$ outtype $=\mathrm{html}$ Date last accessed: November 18, 2010.

51 World Health Organization. Japan Tuberculosis Profile. Geneva, World Health Organization, 2009. Available from https:/ / extranet who.int $/$ sree $/$ Reports?op $=$ Replet\&name $=\% 2 F W H O \_H Q \_R e p o r t s$

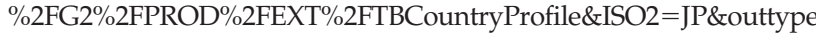
$=\mathrm{html}$ Date last accessed: November 18, 2010. 